\title{
TURBULENCE AND VORTICITY \\ IN THE WAKE OF PALAU
}

By Louis St. Laurent, Takashi Ijichi, Sophia T. Merrifield, Justin Shapiro, and Harper L. Simmons

ABSTRACT. The interaction of flow with steep island and ridge topography at the Palau island chain leads to rich vorticity fields that generate a cascade of motions. The energy transfer to small scales removes energy from the large-scale mean flow of the equatorial current systems and feeds energy to the fine and microstructure scales where instability mechanisms lead to turbulence and dissipation. Until now, direct assessments of the turbulence associated with island wakes have received only minimal attention. Here, we examine data collected from an ocean glider equipped with microstructure sensors that flew in the island wake of Palau. We use a combination of submesoscale modeling and direct observation to quantify the relationship between vorticity and turbulence levels. We find that direct wind-driven mixing only accounts for about $10 \%$ of the observed turbulence levels, suggesting that most of the energy for mixing is extracted from the shear associated with the vorticity field in the island's wake. Below the surface layer, enhanced turbulence correlates with the phase and magnitude of the relative vorticity and strain levels of the mesoscale flow. 
IN PLAIN WORDS. In regions where islands, ridges, and coral reefs protrude to the sea surface, ocean currents collide with land and produce complex flow patterns. The downstream flow is characterized by a turbulent wake where the ocean's properties, such as temperature and salinity, are strongly mixed. Our study examined the turbulent wake that results at Palau, where the equatorial currents of the North Pacific shed a wake around the many islands and reefs that block the flow. We used an autonomous undersea glider that flies repeatedly between the ocean's surface and depth to measure turbulent properties of the wake. Our study indicates that these turbulent properties are closely aligned with the vorticity level of the flow rather than with the direct transfer of energy from the wind.

\section{INTRODUCTION}

The western Pacific region of interest for the Flow Encountering Abrupt Topography (FLEAT) program provided a rich environment for exploring the class of ocean processes that occur when large-scale flows break down into vorticity wakes. In particular, there is generally flow in this region from both the North Equatorial Current (NEC) and the North Equatorial Countercurrent (NECC) in the latitude zone between $5^{\circ} \mathrm{N}$ and $15^{\circ} \mathrm{N}$. As described by Simmons et al. (2019, in this issue), both flows shed strong wakes from the islands of Guam, Yap, and Palau, leaving pronounced signatures in mesoscale vorticity. Eddy features in these flows are also common, and due to mesoscale variability, the flow hitting the island can modulate in both direction and magnitude. This is particularly true when strong El Niño conditions cause variations in winds (e.g., D.J. Webb, 2018) such as during 2015-2016.

Due to its ideal location in the paths of the NEC and NECC flows, the ocean physics at play near Palau have been the focus of numerous past studies (e.g., Schönau and Rudnick, 2015; Colin, 2018) and are the subject of many of the articles presented in this special issue. In particular, Merrifield et al. (2019a, in this issue), Johnston et al. (2019, in this issue), and Simmons et al. (2019, in this issue) all discuss aspects of the vorticity wakes as flow sheds eddies off Palau's many reefs, ridges, and islands.

Here, we present a view of Palau's wake as characterized by direct measurements of turbulence. Such direct measurements of turbulence in island wakes have bulence over an eight-day period, also a distinguishes it among all previous microstructure studies of island wakes.

Our work specifically focuses on Palau during May 2016, when the NEC was shedding a wake to the western side of the islands (Figure 1). Palau consists of many islands and reefs, allowing for complex patterns of circulation as the NEC passes. In particular, the large reef complex to the north of the main island of Babeldaob includes Cormoran Reef and Velasco Reef. While these reefs are very shallow, the passage between them is very deep, allowing for a direct path of flow. To properly understand the flow past and through the islands, high-resolution models of the circulation are required.

To examine the mesoscale forcing of the Palau region during the period of our study, we use the US Navy's global model simulation, the Hybrid Coordinate Ocean Model (HYCOM), which is forced by observed winds and surface fluxes.

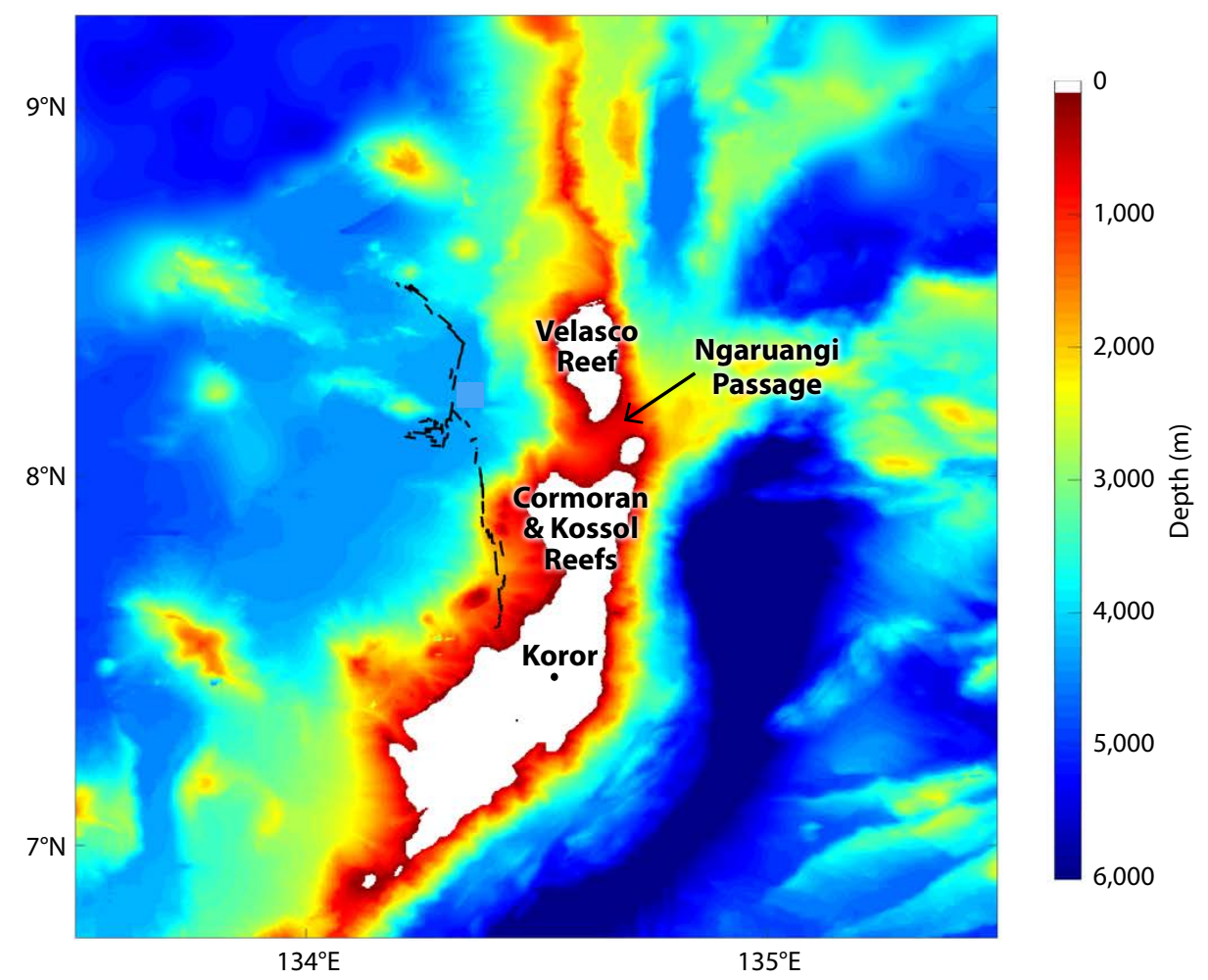

FIGURE 1. Map showing bathymetry around Palau and the track for the turbulence sampling portion of the glider study. Bathymetry shallower than $50 \mathrm{~m}$ is shown in white (including areas above sea level). The glider's GPS fix locations are plotted in black, and the trajectory as shown took eight days with CTD and microstructure sampling to depths between $150 \mathrm{~m}$ and $600 \mathrm{~m}$. The bathymetric data set shown was prepared by Simmons et al. (2019, in this issue), who merged multibeam surveys with reef survey data prepared by the Coral Reef Research Foundation. 
The $1 / 12^{\circ}$ simulation is eddy resolving, with the K-profile parameterization (KPP) implementation of upper ocean mixing processes (Large et al., 1994). We use the Navy Coupled Ocean Data Assimilation (NCODA) version of HYCOM, as described by Cummings and Smedstad (2013). This version assimilates a vast array of observed fields, such as sea surface altimetry and measurements of temperature and salinity, to refine the HYCOM model solution. Many other details of HYCOM and NCODA can be found at https://www.hycom.org/ and in the numerous publications cited there.

During our measurement program, the HYCOM + NCODA flow field compared very well to the glider's flight response, providing validation that the modeled flows represent the mesoscale physics near Palau. Snapshots from the model show the rich detail of the flow as the NEC interacts with the Palau system (Figure 2). During this period, the flow associated with the NEC was from the southeast, and a prominent wake extends from the southern tip of Palau. Over the course of the 10 days shown, there is a strong pulse of flow through the Kossol and Ngaruangi Passages between Cormoran and Velasco
Reefs, leaving a wake pattern on May 15 that advects offshore to the northwest through May 20. As the following material shows, our glider encounters these vorticity features along its transect on the west side of Palau. The wake is most readily quantified using two parameters calculated from the mesoscale velocity components $(U, V)$ and their lateral $(x, y)$ gradients. These are the relative vorticity $\zeta=V_{x}-U_{y}$, and the lateral rate of strain of the flow, $S=\left(\left(U_{x}-V_{y}\right)^{2}+\left(V_{x}+U_{y}\right)^{2}\right)^{1 / 2}$. As described by Thomas et al. (2008), the strain term is used as a measure of the formation of frontal zones, where the cascade of energy from the mesoscale to the submesoscale is enhanced. As such, it is an excellent measure of wake structure. The extent to which regions of enhanced vorticity and strain are also regions of enhanced turbulence is a primary interest of our study.

Figure 2 shows estimates of the lateral strain rate from HYCOM. Gradient values of the modeled flow components were calculated using a centereddifference calculation on the HYCOM $1 / 12^{\circ}$ grid. We depth-integrate $S$ over the upper $150 \mathrm{~m}$ to capture the average dynamics over the layer where the glider spent most of its time. Snapshots of the lateral strain rate are shown for May 10, 15 , and $20(0000 Z)$ as a means of visualizing the wake structure around Palau. In each panel, the glider position at the time of the snapshot is shown (red dot) relative to the preceding 24 hours (red tail). The rate of strain field suggests that the glider encountered strong wake features.

Wind is a fundamental measure of forcing for both the circulation and the turbulence mixing levels of the upper ocean. Unfortunately, measurements of wind are currently not collected by gliders. Moreover, our glider was not accompanied by a research vessel with supporting meteorological measurements. Thus, we must use a shore-based measurement of wind forcing at the time of our glider survey as a reference (Figure 3 ). The Scripps Institution of Oceanographyoperated Expeditionary Weather Station (XMET) on Ongingiang Island, approximately $25 \mathrm{~km}$ south of the southern end of our glider track, offers the closest available data. Merrifield et al. (2019b, in this issue) describe this station and the XMET sensor package. The most energetic winds occurred just prior to the glider deployment. For the duration of the eight-day
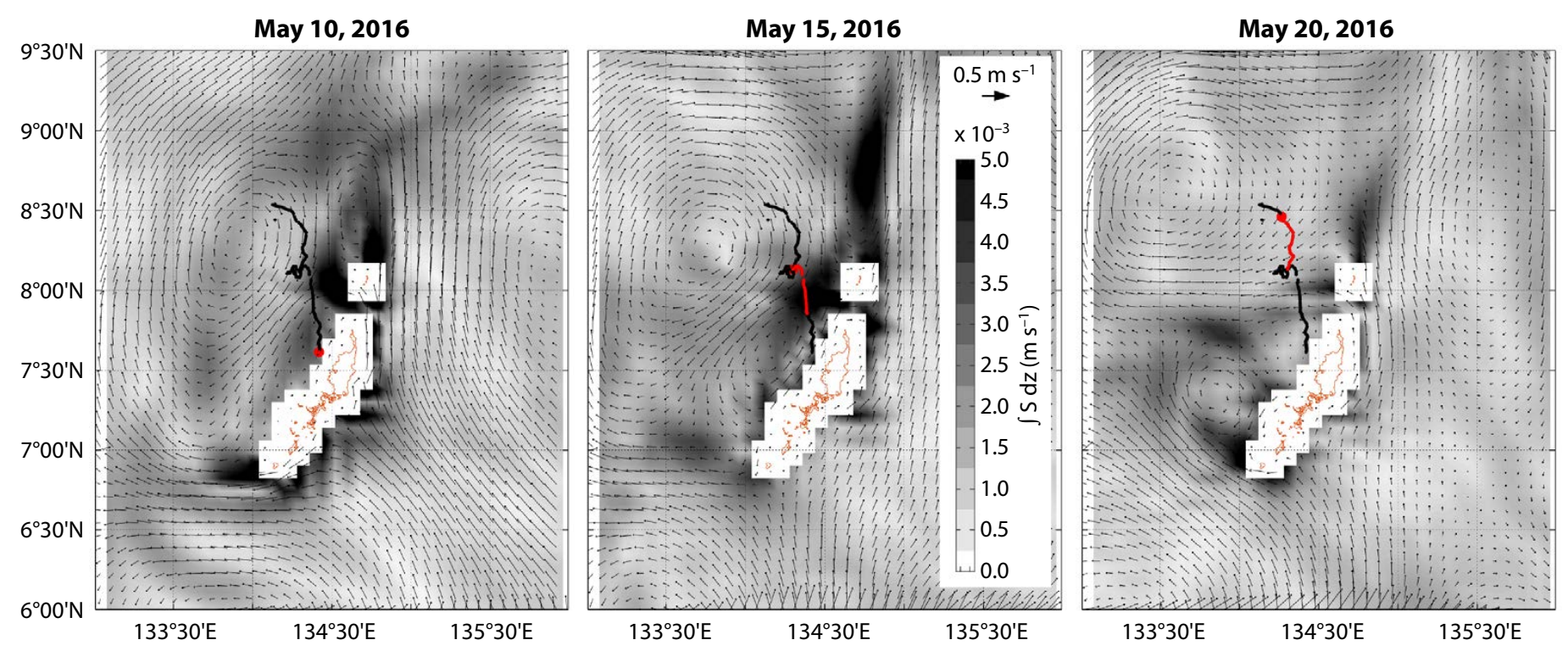

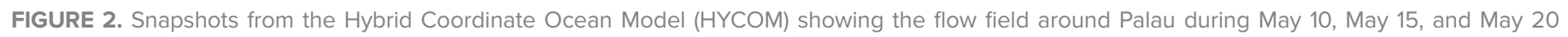

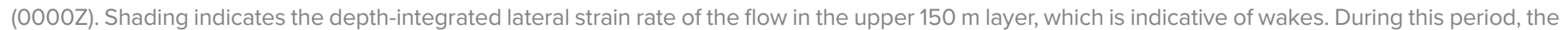

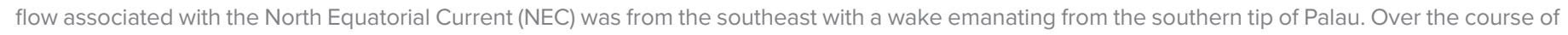

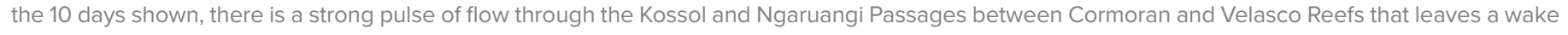

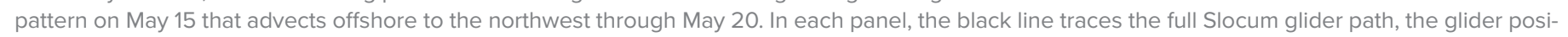
tion at the time of the snapshot is marked with a red dot, and the trajectory for the preceding 24 hours is shown by its red tail. 
glider leg, the winds modulated about a mean speed of about $4 \mathrm{~m} \mathrm{~s}^{-1}$ from the east. These are typical conditions for Palau, where the trade winds are the defining characteristic of the weather.

\section{GLIDER SENSING}

Here, we describe microstructure measurements done using a Teledyne-Webb generation 2 (G2) Slocum ocean glider model. Slocum gliders have been in oceanographic use for about 20 years, and their engineering and science capabilities are described in the literature (e.g., D.C. Webb et al., 2001; Schofield et al., 2007). All gliders operate by adjusting buoyancy in order to move down or up in the water column. Pitch is controlled by moving weight (the battery) fore and aft, changing the moment of inertia relative to the moment of buoyancy. As their names imply, gliders generate lift from their wings to translate vertical motion into lateral flight. On the Slocum platform, a rudder is used to achieve steering. Our glider was also equipped with a thruster, allowing us to activate propulsion as needed to acquire desired flight speed. This capability was used at the end of the mission to fly the glider close to Palau, but the thruster was not used during the data collection period of our study discussed here.

A CTD system located under the starboard wing is the primary sensor of most Slocum gliders, and we used a pumped Sea-Bird Electronics module for temperature and conductivity. Figure 4 shows those data, as collected by our transect. Temperature is the main stratifying agent, and a thermocline at $150 \mathrm{~m}$ separates a strongly stratified warm layer above from weakly stratified cooler waters below. A

FIGURE 4. Temperature and salinity sections as measured by the glider. Time is shown along the lower axis, and latitude along the upper axis. As the glider passed Cormoran Reef (approximately $8^{\circ} \mathrm{N}$ ), it encountered a strong westward flow from Ngaruangi Passage that resulted in an offshore excursion. To restore the intended trajectory toward the north, we flew the glider shallow during days 135 to 137 (May 14-16).

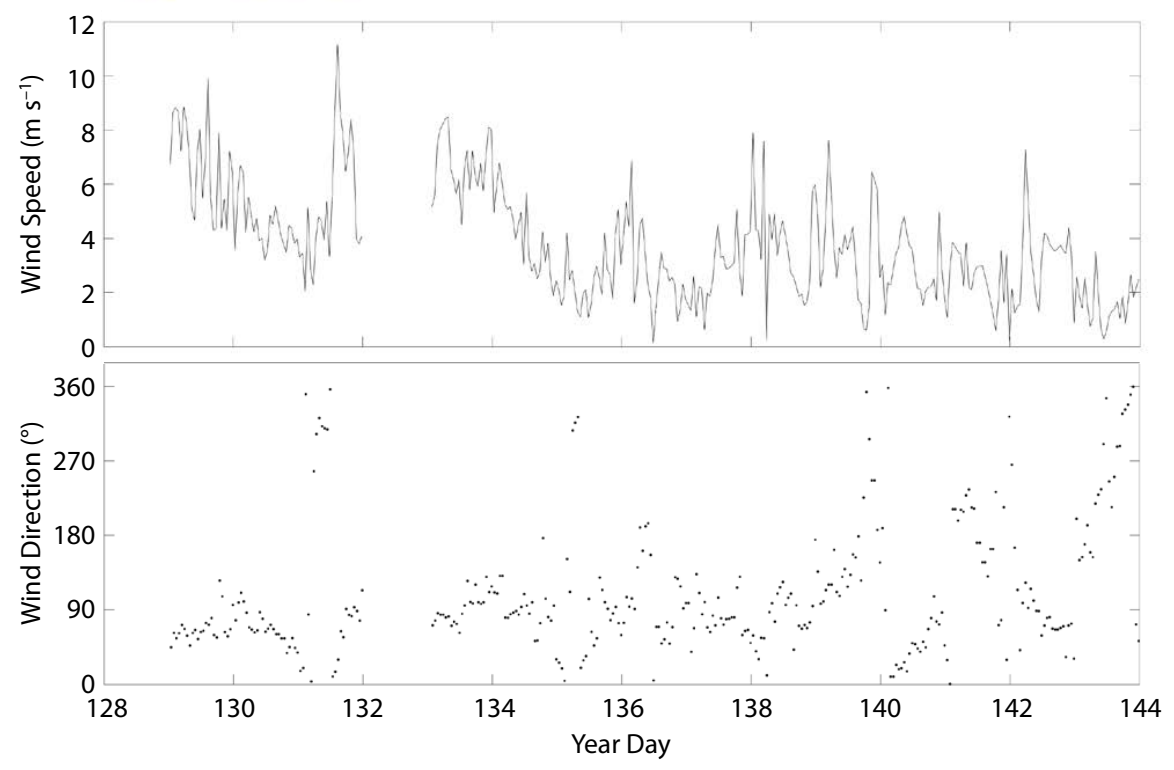

FIGURE 3. Wind speed (top) and direction (bottom) as measured at Palau Scripps Institution of Oceanography-operated Expeditionary Weather Station, located on Ongingiang Island, described by Merrifield et al. (2019b, in this issue). The two-day data gap occurs on days 132-134, corresponding to the beginning of the glider mission. Weather was fair for the entire periodthe strongest winds occurred just before the glider mission on day 131 (May 10).

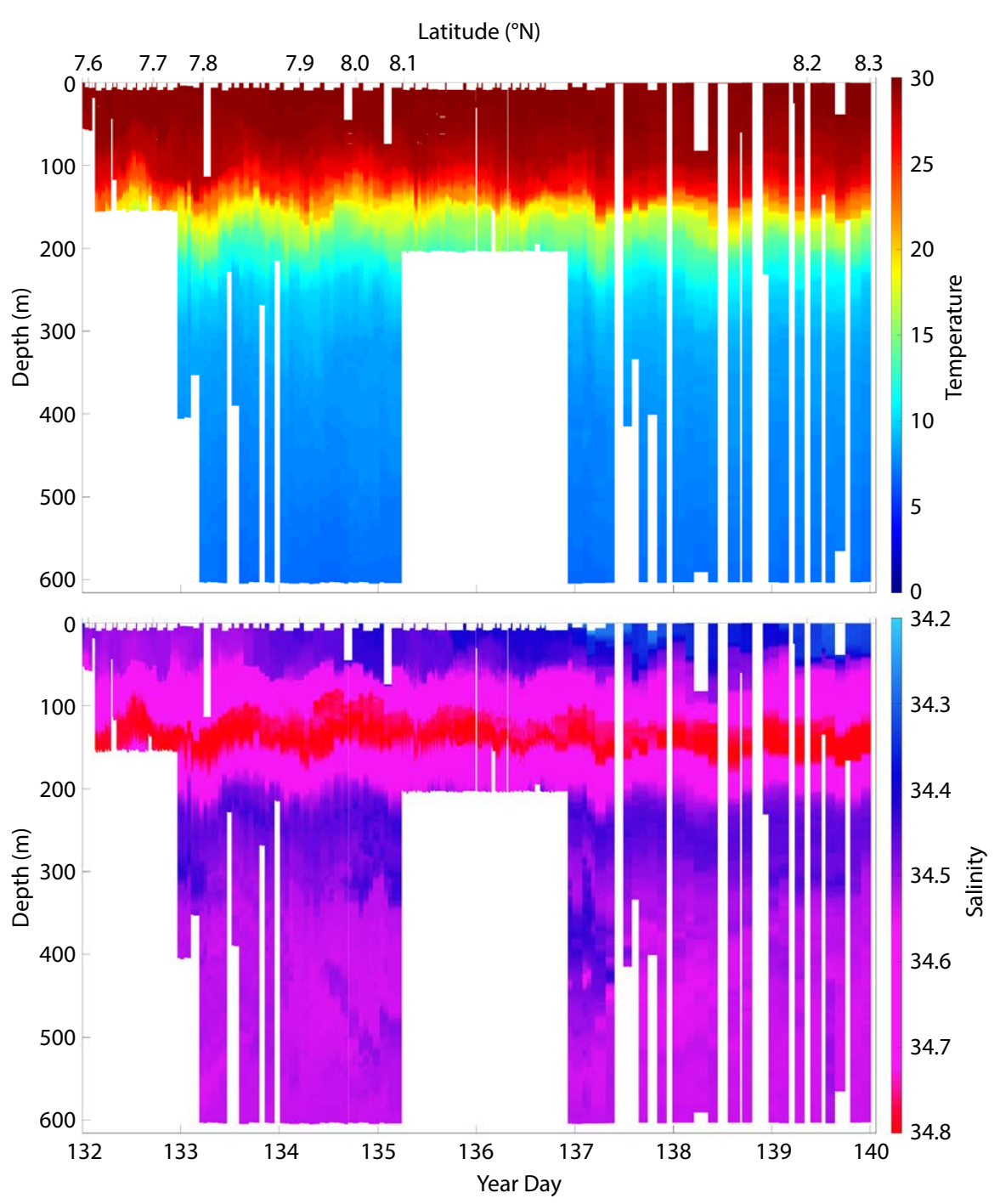


subsurface maximum in salinity is associated with the thermocline. The freshest water is at the surface, fresher to the north of the section, suggesting that flow from Ngaruangi Passage provides a fresher water mass to the western side of Palau.

Our glider-based microstructure sampling capability is provided by a Rockland Scientific Microrider (see photo on the cover of this special issue of Oceanography). The Microrider (MR) is a modular package housing up to six microstructure probes. Internally, the MR chassis also houses a pressure sensor, inclinometers, and accelerometers that provide the motion analysis necessary for the processing of microstructure data.

The MR is nearly neutrally buoyant. However, its placement on the dorsal side of the glider does change the axial moment of the system (also known as the $\mathrm{H}$-moment), which is accounted for in the ballasting of the glider. The MR also adds about $30 \%$ more drag to the vehicle (proportional to the increased spatial area) and a corresponding decrease in the system's maximum speed of about $15 \%$. Most significantly, the MR draws approximately $1 \mathrm{~W}$ while in operation, more than double the hotel load of a standard Slocum running a CTD. In practice, the use of the MR reduces mission duration by about $25 \%$ relative to a system with no MR. Despite the penalties of drag and power draw, the addition of microstructure sensors adds a novel turbulence measurement capability that is unrivaled by other available sampling platforms. Early engineering studies (Wolk et al., 2009) suggest that the dissipation rate noise levels are as low as $3 \times 10^{-11} \mathrm{~W} \mathrm{~kg}^{-1}$, comparable to measurements achieved by the best untethered free-fall profilers. St. Laurent and Merrifield (2017) describe additional data from previous studies using our G2 system.

The dissipation record west of Palau shows turbulence levels from $\mathrm{O}\left(10^{-11}\right)$ to $\mathrm{O}\left(10^{-6}\right) \mathrm{W} \mathrm{kg}^{-1}$ (Figure 5). Enhanced turbulence characterizes the upper $200 \mathrm{~m}$, corresponding to the layer above the subsurface salinity maximum where the stratification is weaker than in the pycnocline below. Winds during the period of the turbulence record were nearly steady at about $5 \mathrm{~m} \mathrm{~s}^{-1}$.

There are two distinct dissipation signals in the record. Enhanced dissipation in the upper $150 \mathrm{~m}$ modulates as a function of wind strength and upper ocean shear. Below $150 \mathrm{~m}$, dissipation levels are markedly weaker. There, enhanced dissi- pation appears to indicate the presence of a deep internal wave field. Specifically, bands of enhanced dissipation appear to slope downward with time, indicative of upward-radiating internal waves (e.g., Munk, 1981). Notably, this deep signal is considerably stronger to the south of Ngaruangi Passage than to the north. This leads to a disparity in the background levels of dissipation, from $\mathrm{O}\left(10^{-10}\right) \mathrm{W} \mathrm{kg}^{-1}$ on the south side of the passage to $\mathrm{O}\left(10^{-11}\right) \mathrm{W} \mathrm{kg}^{-1}$ north of the passage. The internal wave pattern is less apparent to the north of the passage, although this could be an illusion based on sparser sampling and the general position of the glider relative to the likely source of the internal waves.

The likely source of the deep dissipation signal is the seamount bathymetry to the west of Ngaruangi Passage. The glider came particularly close to these seamounts during its westward excursion when it encountered flow through the passage. Moreover, the glider lingered slightly to the south of the seamounts for the better part of two days, accumulating many samples of dissipation rates in close proximity to the generation signal. The diminished signal to the north of the passage is most likely due to the glider's increas-

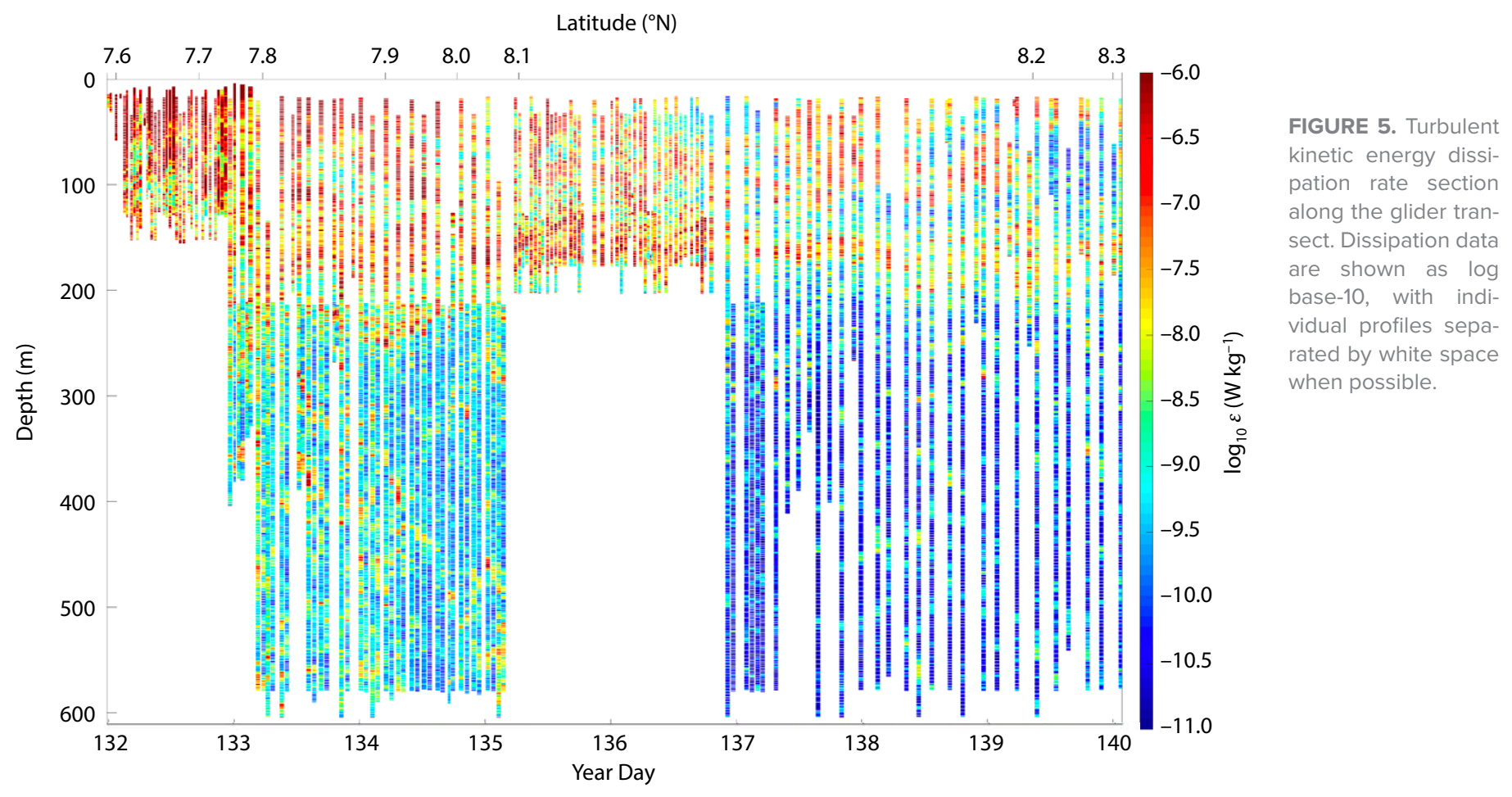


ing distance from the signal. The rapid decay of enhanced shear away from the seamounts is consistent with high-mode internal wave energy that decays rapidly (e.g., St. Laurent and Garrett, 2002).

Dissipation rate estimates are used to calculate vertical mixing rates associated with buoyancy. This is typically defined as a diffusivity, $k_{\rho}$, generally calculated from a model described by Osborn (1980). To define a meaningful diffusivity, large ensemble averages of the dissipation rate population must be used. Our record consists of approximately 130,000 independent estimates of dissipation rate, com-

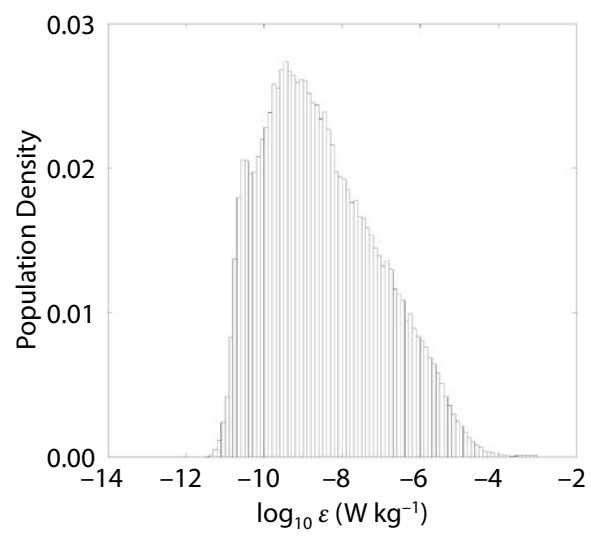

FIGURE 6. Population distribution of dissipation rate estimates from the eight-day glider record. Dissipation ranges from about $1 \times 10^{-11} \mathrm{~W} \mathrm{~kg}^{-1}$ to $1 \times 10^{-3} \mathrm{~W} \mathrm{~kg}^{-1}$, the former being the minimum noise level of the sensor, and the latter being the limiting sensitivity of the shear probe. The lesser mode of dissipation rate centered at $3 \times 10^{-11} \mathrm{~W} \mathrm{~kg}^{-1}$ represents the quieter region north of Ngaruangi Passage. The general skew in the distribution, as characterized by the left side being steeper than the more Gaussian right side, is caused by the lack of dissipation rates lower than $1 \times 10^{-11} \mathrm{~W} \mathrm{~kg}^{-1}$, which fall below the noise level of the sensor. Such values are aliased into the records slightly greater than the noise level, producing the shoulder on the left side of the distribution.

FIGURE 7. Mean profiles of (a) turbulent dissipation rate, and (b) turbulent diffusivity. These estimates reflect the mean of 245 profiles of dissipation collected by the glider, comprised of over 130,000 estimates of epsilon. Mean ensembles were done for $50 \mathrm{~m}$ depth bins, and average (blue line) and 95\% confidence intervals (blue shaded band) are shown. The open ocean thermocline background for dissipation rate and diffusivity are about $1 \times 10^{-10} \mathrm{~W} \mathrm{~kg}^{-1}$ and $1 \times 10^{-5} \mathrm{~m}^{2} \mathrm{~s}^{-1}$, respectively, as indicated by the left edge of the gray shading. prising a large approximately log-normal distribution (Figure 6). To produce diffusivity estimates, we average the 245 profiles of dissipation shown in Figure 5 into $50 \mathrm{~m}$ depth bins, producing a single ensemble mean dissipation rate profile (Figure 7a).

Mean dissipation rates from each $50 \mathrm{~m}$ bin are used to produce an estimate of diffusivity using $k_{\rho}=\Gamma\langle\varepsilon\rangle / \overline{N^{2}}$ where $\Gamma$ is the mixing efficiency parameter and $\overline{N^{2}}$ is the mean buoyancy gradient. The mixing efficiency parameter is taken to have a value of 0.2 (Osborn, 1980). Though the exact value is subject to fluctuations due to variations in ocean processes, 0.2 has repeatedly been established as appropriate for describing large ensemble averages of mixing processes (Ijichi and Hibiya, 2018; Gregg et al., 2018).

Figure $7 \mathrm{~b}$ shows the mean diffusivity. The canonical value of diffusivity in the thermocline of the open sea, away from topography, is $1 \times 10^{-5} \mathrm{~m}^{2} \mathrm{~s}^{-1}$ (e.g., St. Laurent and Simmons, 2006). Our survey region just west of Palau shows diffusivities $\mathrm{O}(1)$ to $\mathrm{O}(1,000)$ larger than this. The upper $50 \mathrm{~m}$ layer experiences dissipation levels directly forced by the winds, including the effects of wind stress (see below). Large dissipation and diffusivity levels in the near-surface layer are common, though the latter are often associated with small buoyancy gradient levels (as $k_{\rho}$ is inversely propor-

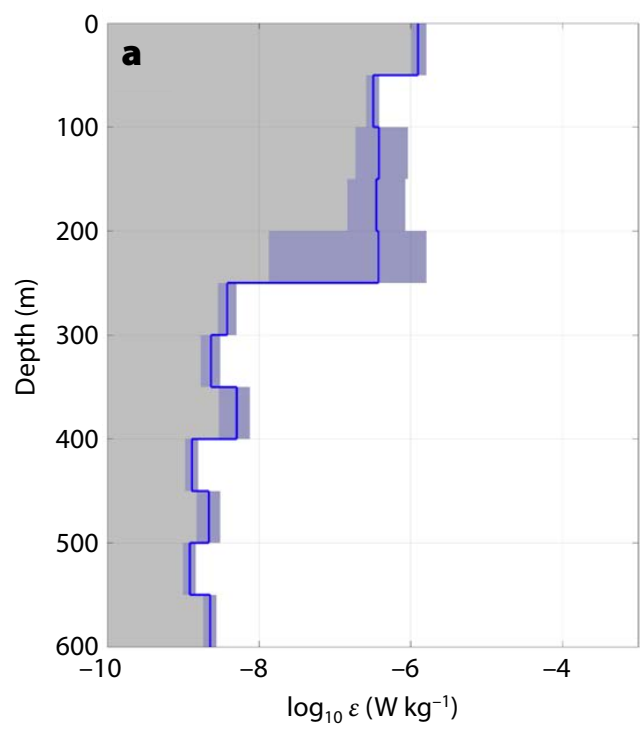

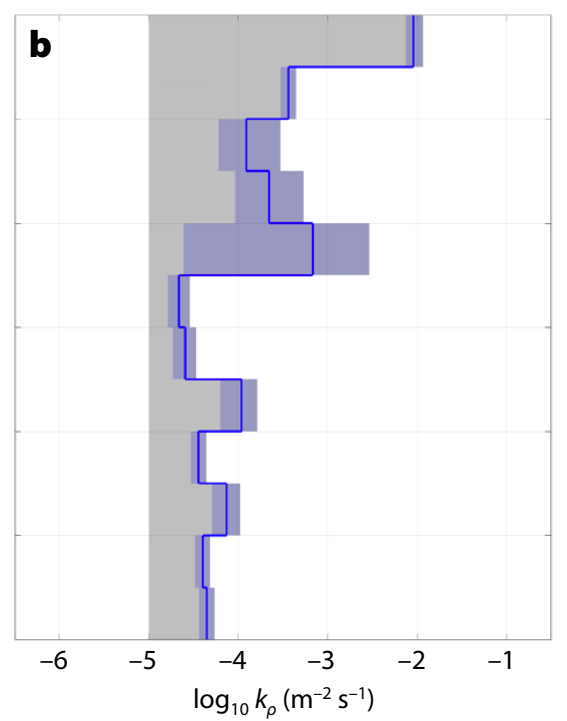

tional to $N^{2}$ ), indicating that such mixing is not resulting in much buoyancy flux. Below the upper $50 \mathrm{~m}$, we find enhanced mixing through the upper $200 \mathrm{~m}$, which includes the strongly stratified layer near $150 \mathrm{~m}$ where the salinity maximum occurs. Below $200 \mathrm{~m}$ depth, diffusivity levels are still three to 10 times larger than typical open ocean mixing levels.

\section{DISCUSSION}

As described above, our glider record west of Palau showed turbulence and mixing levels enhanced above those of the typical open ocean. In the upper ocean, this enhancement includes not only the near-surface layer but also the highly stratified layer characterizing the upper $200 \mathrm{~m}$ of the water column. This clearly indicates an energy source driving the cascade to turbulent energy.

The most obvious sources of turbulence in the upper ocean are those imposed by the atmosphere: convective forces from buoyancy loss and wind stress (e.g., Lombardo and Gregg, 1989). In the case of Palau, the most likely source of convective buoyancy loss is either conduction (heat loss) at the surface by the wind, or evaporative heat loss. During our period of observation (May10-20, 2016), the sea surface temperature was between $29.5^{\circ} \mathrm{C}$ and $30^{\circ} \mathrm{C}$, while the air temperature varied from $25^{\circ} \mathrm{C}$ to $33^{\circ} \mathrm{C}$, with the cooler air temperatures occurring in the 
evening. During these evening periods, the maximum heat loss from the ocean is calculated to be about $Q=15 \mathrm{~W} \mathrm{~m}^{-2}$ (equally from conduction and evaporation, as calculated from the COARE 3.6 code of Fairall et al., 2003). To convert this to a buoyancy flux in the ocean surface layer, we take $J_{0}=g \alpha Q /\left(\rho c_{p}\right)$, where $c_{p}$ is the specific heat of seawater and $\alpha$ is the thermal expansion coefficient. The associated buoyancy flux is $10^{-8} \mathrm{~W} \mathrm{~kg}^{-1}$, which can yield an equivalent level of dissipation in a convective layer near the surface. This convective mechanism of dissipation would only occur in the evenings when the air is cooler than the sea (Lombardo and Gregg, 1989). Unlike typical observations in the mid-latitudes, the dissipation levels documented here do not show evidence of diurnal convection.

The potential role of convective mixing must be assessed relative to the depth of the mixed layer $(D)$ and the MoninObukhov length scale $(L)$. The former can be defined by the observed density measurements. As measured by a density

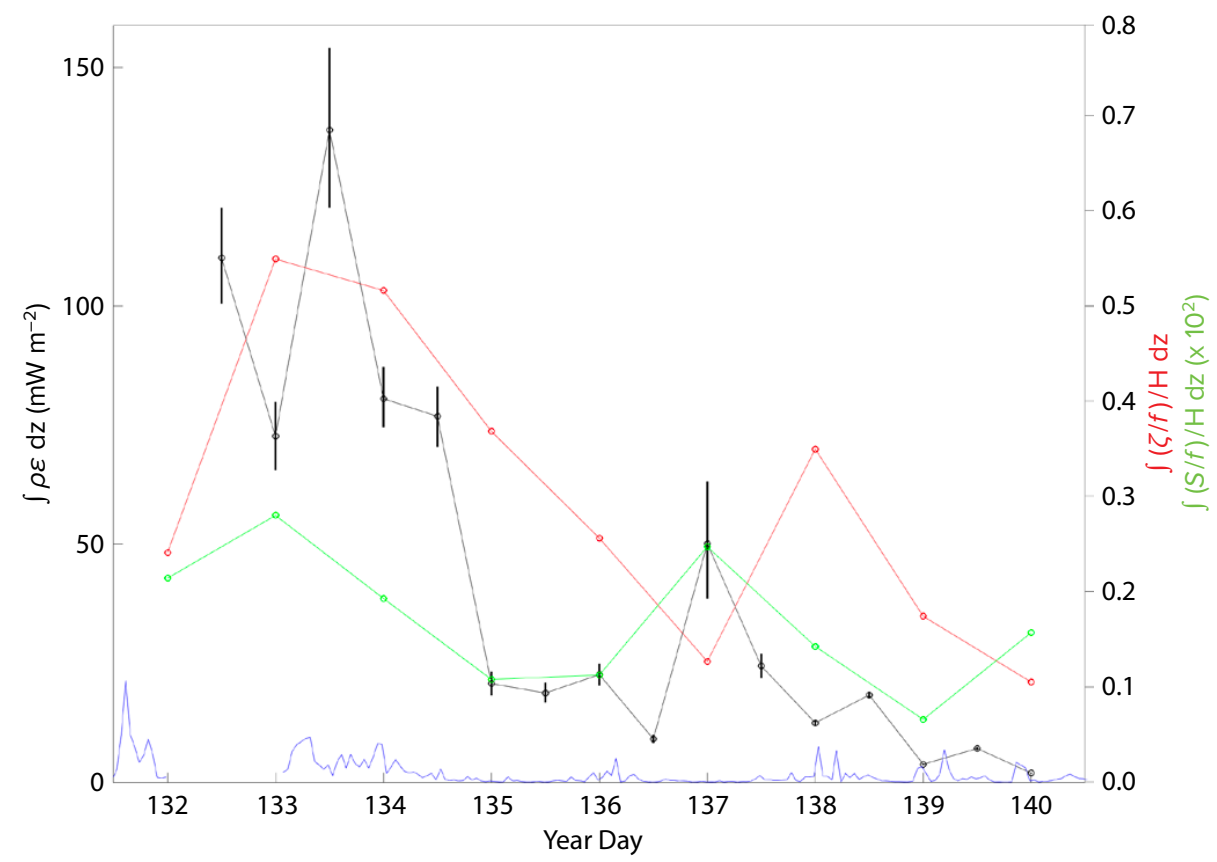

FIGURE 8. Composite plot showing depth-integrated quantities for dissipation rates (black), windstress inferred dissipation (blue), and normalized relative vorticity (red) and lateral strain (green). Measured dissipation rates were multiplied by density and vertically integrated to $150 \mathrm{~m}$ depth, and values are shown with their $95 \%$ confidence intervals. As a means of direct comparison, the dissipation rate associated with wind stress was also calculated and is shown in blue. Vertically integrated relative vorticity and strain rate, as estimated using the HYCOM model (see Figure 2 and text), is also presented, as normalized by the planetary vorticity $(f)$ and the integration depth $(H=150 \mathrm{~m})$. The corresponding axis for these nondimensional values is on the right. given by $z<<L$ (Lombardo and Gregg, 1989). We will take this limit to be that of the average mixed layer depth of $30 \mathrm{~m}$.

As Figure 8 shows, integrated levels of the turbulent dissipation rate are used to calculate dissipated power. Measured dissipated power (black signal, with error bars) does follow the general trend exhibited by the wind-induced power (blue signal), but it is an order of magnitude larger. This implies that the energy for dissipation in the upper ocean must come from a source much more energetic than the winds. Such energy is readily available in the vorticity of the mesoscale flow.

While there is no closure theory for how energy associated with the vorticity field cascades via mechanical energy transfer to ocean dissipation, we can examine the trend of depth-integrated vorticity and lateral strain as estimated from the HYCOM model simulations shown in Figure 2. For purposes of comparison to the integrated dissipation rates, we depth-integrate the quantities $\zeta / f$ and $S / f$ and normalize by the integration depth $(D)$. Figure 8 plots the resulting nondimensional quantities relative to integrated dissipation levels.

As anticipated, there is strong association between the records of integrated dissipation, integrated vorticity, and integrated strain. Statistically, the records have a $(0.7 \pm 0.2)$ correlation coefficient. Both records are characterized by two peaks in signal. The first occurs in days 133 to 135 of the record. This corresponds to the period when the glider encountered the wake created at the southern tip of the island (Figure 2, middle panel). This period exhibits the largest vorticity levels, and also the largest dissipation levels. The second period of enhanced activity occurs during days 137 to 139 , corresponding to the period when flow through Ngaruangi Passage sheds a wake just south of Velasco Reef. Each of these periods of enhanced vorticity and dissipation also have associated bursts of wind activity (as indicated by the log-layer estimates of wind-stress implied dissipation). The level to which 
dissipation modulates with vorticity at finer levels of detail, such as those visible in higher-resolution numerical simulations (e.g., Simmons et al., 2019, in this issue) is the subject of ongoing work.

While our analysis shows a clear relation between the modulation of vorticity and dissipation levels, it does not by itself provide much insight into the physical mechanisms of the cascade processes that transfer energy from the mesoscale to the turbulence scale. Presumably, these mechanisms must be of the general class of processes described as mixed-layer instabilities (Boccaletti et al., 2007; Callies et al., 2016). Like all processes that lead to turbulence, these instabilities must transfer energy through the meso- and submesoscale fields to scales of shear that favor turbulence. A clear record of direct observation of this collection of processes does not yet exist but may be possible in the near future through the combined use of modeling and autonomous measurement technologies. The vorticity field of the Palau wake would be an ideal location to observe such a cascade.

\section{REFERENCES}

Boccaletti, G., R. Ferrari, and B. Fox-Kemper. 2007. Mixed layer instabilities and restratification. Journal of Physical Oceanography 37(9):2,228-2,250, https://doi.org/10.1175/JP03101.1.

Callies, J., G. Flierl, R. Ferrari, and B. Fox-Kemper. 2016. The role of mixed-layer instabilities in submesoscale turbulence. Journal of Fluid Mechanics 788:5-41, https://doi.org/10.1017/ jfm.2015.700.

Chang, M.-H., T.Y. Tang, C.-R. Ho, and S.-Y. Chao. 2013. Kuroshio-induced wake in the lee of Green Island off Taiwan. Journal of Geophysical Research 118(3):1,508-1,519, https://doi.org/10.1002/ jgrc. 20151.

Colin, P.L. 2018. Ocean warming and the reefs of Palau. Oceanography 31(2):126-135, https://doi.org/ 10.5670/oceanog.2018.214.

Cummings, J.A., and O.M. Smedstad. 2013. Variational data assimilation for the global ocean. Pp. 303-343 in Data Assimilation for Atmospheric, Oceanic and Hydrologic Applications, vol. II. S.K. Park and L. Xu, eds, Springer-Verlag Berlin Heidelberg.

Fairall, C.W., E.F. Bradley, J.E. Hare, A.A. Grachev, and J.B. Edson. 2003. Bulk parameterization of air-sea fluxes: Updates and verification for the COARE algorithm. Journal of Climate 16:571-591, https://doi.org/10.1175/1520-0442(2003)016 $<0571$ :BPOASF>2.0.CO;2.

Gregg, M.C., E.A. D’Asaro, J.J. Riley, and E. Kunze. 2019. Mixing efficiency in the ocean. Annual Review of Marine Science 10:443-473, https://doi.org/ 10.1146/annurev-marine-121916-063643.

Hasegawa, D., H. Yamazaki, R.G. Lueck, and L. Seuront. 2004. How islands stir and fertilize the upper ocean. Geophysical Research Letters 31, L16303, https://doi.org/10.1029/2004GL020143.
Hasegawa, D., M.R. Lewis, and A. Gangopadhyay. 2009. How islands cause phytoplankton to bloom in their wakes. Geophysical Research Letters 36(20), https://doi.org/10.1029/ 2009 GL039743.

Ijichi, T., and T. Hibiya. 2018. Observed variations in turbulent mixing efficiency in the deep ocean. Journal of Physical Oceanography 48:1,815-1,830, https://doi.org/10.1175/JPO-D-17-0275.1.

Johnston, T.M.S., J.A. MacKinnon, P.L. Colin, P.J. Haley Jr., P.F.J. Lermusiaux, A.J. Lucas, M.A. Merrifield, S.T. Merrifield, C. Mirabito, J.D. Nash, and others. 2019. Energy and momentum lost to wake eddies and lee waves generated by the North Equatorial Current and tidal flows at Peleliu, Palau. Oceanography 32(4):110-125, https://doi.org/10.5670/oceanog.2019.417.

Large, W.G., J.C. McWilliams, and S.C. Doney. 1994. Oceanic vertical mixing: A review and a model with a nonlocal boundary layer parameterization. Reviews of Geophysics 32:363-403, https://doi.org/10.1029/94RG01872.

Lombardo, C., and M.C. Gregg. 1989. Similarity scaling of viscous and thermal dissipation in a convecting surface boundary layer. Journal of Geophysical Research 94(C5):6,273-6,284, https://doi.org/ 10.1029/JC094iC05p06273.

MacKinnon, J.A., M.H. Alford, G. Voet, K. Zeiden, T.M.S. Johnston, M. Siegelman, S. Merrifield, and M. Merrifield. 2019. Eddy wake generation from broadband currents near Palau. Journal of Geophysical Research 124:4,891-4,903, https://doi.org/10.1029/2019JC014945.

Merrifield, S.T., P.L. Colin, T. Cook, C. GarciaMoreno, J.A. MacKinnon, M. Otero, T.A. Schramek, M. Siegelman, H.L. Simmons, and E.J. Terrill. 2019. Island wakes observed from high-frequency current mapping radar. Oceanography 32(4):92-101, https://doi.org/10.5670/oceanog.2019.415.

Merrifield, S.T., T.A. Schramek, S. Celona, A.B. Villas Bôas, P.L. Colin, and E.J. Terrill. 2019. Typhoon-forced waves around a western Pacific island nation. Oceanography 32(4):56-65, https://doi.org/10.5670/oceanog.2019.411.

Munk, W. 1981. Internal waves and small-scale mixing processes. Pp. 264-290 in Evolution of Physical Oceanography. B.A. Warren and C. Wunsch, eds, MIT Press.

Osborn, T.R. 1980. Estimates of the local rate of vertical diffusion from dissipation measurements. Journal of Physical Oceanography 10(1):83-89, https://doi.org/10.1175/1520-0485(1980)010<0083: EOTLRO $>2.0 . C O ; 2$.

Schofield, O., J. Kohut, D. Aragon, L. Creed, J. Graver, C. Haldeman, J. Kerfoot, H. Roarty, C. Jones, D. Webb, and S. Glenn. 2007. Slocum gliders: Robust and ready. Journal of Field Robotics 24(6):473-485, https://doi.org/10.1002/ rob.20200.

Schönau, M.C., and D.L. Rudnick. 2015. Glider observations of the North Equatorial Current in the western tropical Pacific. Journal of Geophysical Research 120:3,586-3,605, https://doi.org/ 10.1002/2014JC010595.

Simmons, H.L., B.S. Powell, S.T. Merrifield, S.E. Zedler, and P.L. Colin. 2019. Dynamical downscaling of equatorial flow response to Palau. Oceanography 32(4):84-91, https://doi.org/ 10.5670/oceanog.2019.414.

St. Laurent, L., and C. Garrett. 2002. The role of internal tides in mixing the deep ocean. Journal of Physical Oceanography 32:2,882-2,899, https://doi.org/10.1175/1520-0485(2002)032 $<2882$ :TROITI $>2$.0.CO;2.

St. Laurent, L., and H. Simmons. 2006. Estimates of power consumed by mixing in the ocean interior Journal of Climate 19:4,877-4,890, https://doi.org/ 10.1175/JCLI3887.1.

St. Laurent, L., and S. Merrifield. 2017. Measurements of near-surface turbulence and mixing from autonomous ocean gliders. Oceanography 30(2):116-125, https://doi.org/10.5670/oceanog.2017.231.
Thomas, L., A. Tandon, and A. Mahadevan. 2008. Submesoscale ocean processes and dynamics. Pp. 17-38 in Ocean Modeling in an Eddying Regime. M. Hecht and H. Hasume, eds, Geophysical Monograph 177, American Geophysical Union, Washington, DC.

Webb, D.C., P.J. Simonetti, and C.P. Jones. 2001 SLOCUM: An underwater glider propelled by environmental energy. IEEE Journal of Oceanic Engineering 26(4):447-452, https://doi.org/ 10.1109/48.972077.

Webb, D.J. 2018. On the role of the North Equatorial Counter Current during a strong EI Niño. Ocean Science 14:633-660, https://doi.org/10.5194/ os-14-633-2018.

Weller, R.A., and A.J. Pleuddemann. 1996. Observations of the vertical structure of the oceanic boundary layer. Journal of Geophysical Research 101:8,789-8,806, https://doi.org/ 10.1029/96JC00206.

Wolk, F., R.G. Lueck, and L. St. Laurent. 2009. Turbulence measurements from a glider. Pp. 1-6 in Marine Technology for Our Future: Global and Local Challenges. MTS/IEEE.

\section{ACKNOWLEDGMENTS}

We thank the Palau National Government for permission to carry out the research in Palau. We also thank the US Office of Naval Research for supporting this work. We especially thank Pat and Lori Colin of the Coral Reef Research Foundation and their team for accommodating our research team in Koror, Palau, and running vessel operations in support of glider deployments and recoveries. Sean Whelan of the Woods Hole Oceanographic Institution and Lance Braasch of Scripps Institution of Oceanography provided technical support in the field. Funding for the development of HYCOM has been provided by the National Ocean Partnership Program and the Office of Naval Research. Data assimilative products using HYCOM are funded by the US Navy. Computer time was made available by the Department of Defense High Performance Computing Modernization Program. The output is publicly available at https://www.hycom.org/.

\section{AUTHORS}

Louis St. Laurent (Istlaurent@apl.uw.edu) is Senior Principal Oceanographer, Applied Physics Laboratory, University of Washington, Seattle, WA, USA. Takashi ljichi is Postdoctoral Fellow, Woods Hole Oceanographic Institution, Woods Hole, MA, USA. Sophia T. Merrifield is Project Scientist, Scripps Institution of Oceanography, University of California San Diego, La Jolla, CA, USA. Justin Shapiro is Principal Research Engineer, Applied Physics Laboratory, University of Washington, Seattle, WA, USA. Harper L. Simmons is Associate Professor, College of Fisheries and Ocean Sciences, University of Alaska Fairbanks, Fairbanks, AK, USA.

\section{ARTICLE CITATION}

St. Laurent, L., T. Ijichi, S.T. Merrifield, J. Shapiro, and H.L. Simmons. 2019. Turbulence and vorticity in the wake of Palau. Oceanography 32(4):102-109, https://doi.org/10.5670/oceanog.2019.416.

\section{COPYRIGHT \& USAGE}

This is an open access article made available under the terms of the Creative Commons Attribution 4.0 International License (https://creativecommons.org/ licenses/by/4.0/), which permits use, sharing, adaptation, distribution, and reproduction in any medium or format as long as users cite the materials appropriately, provide a link to the Creative Commons license, and indicate the changes that were made to the original content. 